\section{EMBRYRIDDLE \\ Aeronautical University}

SCHOLARLY COMMONS
International Journal of Aviation, Aeronautics, and Aerospace

\title{
Effects of a hand luggage guiding system on airplane boarding time and passenger experience
}

\author{
Mirte Vendel \\ mirtevendel@hotmail.com \\ Sagar Dangal \\ Delft University of Technology, sagardangal@hotmail.com \\ Jessica Coppens \\ Delft University of Technology, jessica-coppens@hotmail.com \\ Suzanne Hiemstra-van Mastrigt \\ Delft University of Technology, S.Hiemstra-vanMastrigt@tudelft.nl \\ Peter Vink \\ Delft University of Technology, p.vink@tudelft.nl
}

Follow this and additional works at: https://commons.erau.edu/ijaaa

Part of the Industrial Engineering Commons, Management and Operations Commons, and the Systems Engineering and Multidisciplinary Design Optimization Commons

\section{Scholarly Commons Citation}

Vendel, M., Dangal, S., Coppens, J., Hiemstra-van Mastrigt, S., \& Vink, P. (2019). Effects of a hand luggage guiding system on airplane boarding time and passenger experience. International Journal of Aviation, Aeronautics, and Aerospace, 6(3). https://doi.org/10.15394/ijaaa.2019.1333

This Article is brought to you for free and open access by the Journals at Scholarly Commons. It has been accepted for inclusion in International Journal of Aviation, Aeronautics, and Aerospace by an authorized administrator of Scholarly Commons. For more information, please contact commons@erau.edu. 


\section{Effects of a hand luggage guiding system on airplane boarding time and passenger experience}

\section{Cover Page Footnote}

The authors would like to thank all the participants for volunteering in this study. This study has been part of the research project PASSME, which has received funding from the European Union's Horizon 2020 research and innovation programme under grant agreement No 636308.

This article is available in International Journal of Aviation, Aeronautics, and Aerospace: https://commons.erau.edu/ 


\section{Introduction}

Airplane boarding is a time-consuming procedure due to a number of factors. First of all, passengers cannot pass each other in the aisles (Steffen \& Hotchkiss, 2011). People also experience stress in finding the seat (Jaehn \& Neumann, 2015) or the space to store their luggage and some passengers repack their luggage in the aisle. Finally, it might happen that suitcases have to be put in the hold at the very last moment due to a lack of space in the overhead luggage bins. According to Van der Broek (2015), none of the narrow body airplanes have sufficient capacity to stow a hand luggage trolley for every passenger on a fully booked flight. Besides, when passengers place the luggage randomly in the bins near their seat, they most likely do not make optimal use of the available space in the bins. In addition, Kierzokwoski and Kisiel (2017) suggested that traditional hand luggage handling of passengers is one of the factors for increase in boarding time. Therefore, this research specifically focused on aforementioned inconveniences during boarding caused by the current way of storing and placing hand luggage in the overhead bins. For this, an improved system was developed (a guiding hand luggage system: GHL-System) and an user test was performed to compare the new system with the current boarding process.

\section{Research Question}

The purpose of the guiding hand luggage system (GHL-System) is to reduce the boarding time and improve the overall boarding experience in order to contribute to the aims of the PASSME (2017) project. The main question is whether this system has a significant effect on boarding time and passenger experience. Therefore, the following research question is formulated:

How does the developed Guiding Hand Luggage System (GHL-System) impact the boarding time and boarding experience compared to traditional boarding?

\section{Method and Materials}

\section{Guiding Hand Luggage System (GHL-System)}

The GHL-System was developed to reduce the boarding time and improve the boarding experience of passengers. This system enables airlines to collect data about the hand luggage dimensions before boarding via scanning devices at the airport, a smartphone application, and/or the airline check-in website. The data is used to calculate the optimal way to make hand luggage fit in the overhead bins in order to optimise the usage of the available space.

The GHL-System includes several elements and actions throughout the air travellers' journey: 
- Passengers are asked to provide the airline with their hand luggage dimensions while booking their ticket or checking in (on the application, the website, or at the check-in desk). Passengers who provide the airline with this information can/will board first.

- An algorithm calculates the optimal hand luggage division in the overhead bins to make these fit. Passengers, for whom the luggage will not fit, will be asked to check-in their hand luggage.

- The other passengers, who do not have to check-in their luggage, will get their own reserved luggage storage spot in the overhead bins. A message will inform the passengers via their mobile device or an email.

- To help passengers find their own reserved luggage spot while boarding, a light strip, icons, and numbers are used to highlight each luggage spot. In the airplane, electronic paper is attached to the ceiling of each overhead bin. These dynamic electronic displays (Figures 1 and 2) show the division outlines, the seat number of the passenger assigned to the specific luggage spot, and a corresponding luggage icon (e.g. suitcase, jacket or backpack).

- To improve the usability and reduce the stress levels of the user, lightemitting diode (LED) strips are installed inside each bin (Figures 1 and 2) to guide the user with suitable light effects. These lights will drag the attention of the passengers toward the correct bin and indicate which part of the bin is meant for that particular piece of hand luggage. The different light effects are explained in more detail below.

This research and the conducted user test were only focused on the boarding process itself, to measure a possible impact of the GHL-System on the boarding time and passengers' experience. 


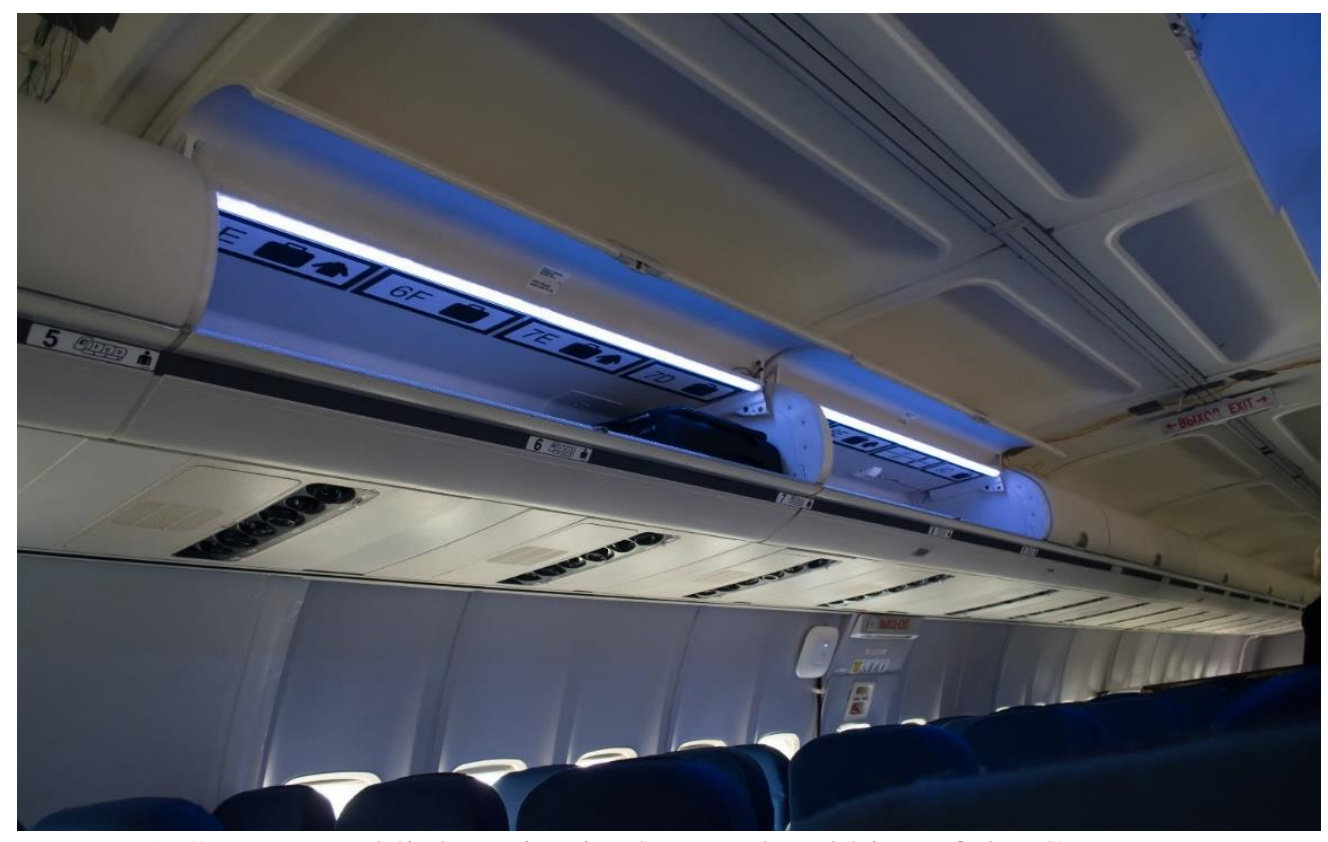

Figure 1. Screens and light strips in the overhead bins of the GHL system installed in B737 test fuselage.

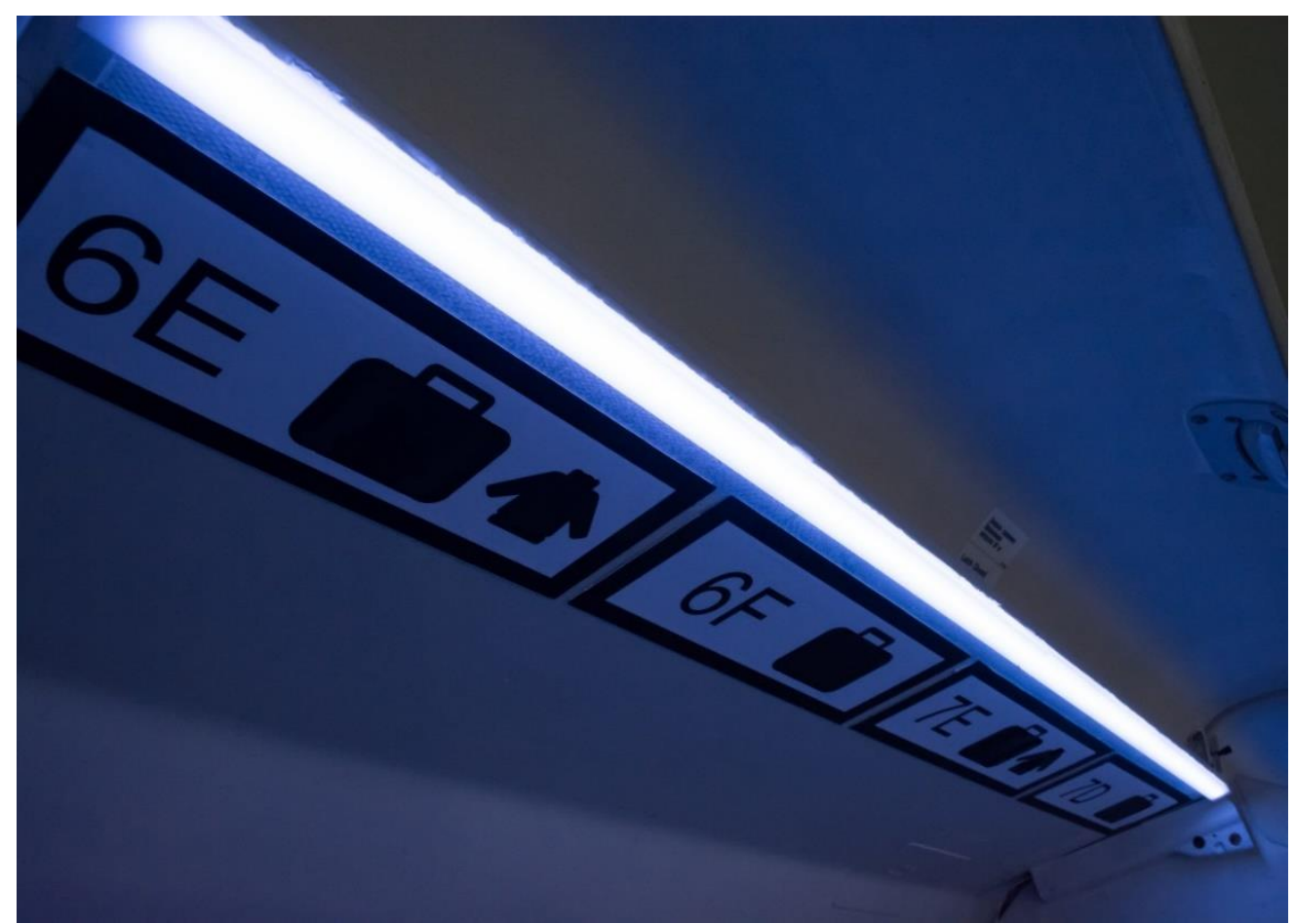

Figure 2. Luggage divisions including a light strip, an outline, seat number, and icon. 


\section{Light Effects}

When boarding with the GHL-System, the light-emitting diodes (LEDs) light up in the bins with a white-blue colour, called the 'mood light'. This mood light is meant to create a calm and relaxed atmosphere where it is easy to find your way. This blue colour is chosen for several reasons. Researchers suggest blue light increases subjective and objective alertness (Iskra-Golec, Wazna, \& Smith, 2012). In addition, blue colour suggests to provide high visibility and can be helpful in improving visual performance (Luo, Zhao, Zhai, Lui, \& Wang, 2013). Furthermore, lighting conditions that improve visibility also indicate in task performance (Veitch, Newsham, Boyce, \& Jones, 2008).

When a passenger approaches his or her luggage spot, the light colour in that specific part of the bin turns white. The changing colour is used to attract the attention of the approaching and searching passenger. At the start, the white light is low in brightness, but it lights up when the passenger comes closer.

Once arrived at the right spot of the overhead bin, the bright white light starts blinking. This effect is added to confirm that the participant has reached the luggage storage space and to draw even more attention towards the luggage spot in case the passenger did not notice the white light before. It will continue blinking until the next action (placing the luggage in the bin) is fulfilled. When the luggage is placed correctly, the light turns green as a confirmation. Afterward, the light will slowly dim and change back to the blue mood light colour. In the case where the luggage is place incorrectly, the light turns red until the placement is corrected. The luggage division is shown in the Appendix.

\section{Protocol}

Two groups of 18 participants were asked to board a Boeing 737 test fuselage on the campus of Delft University of Technology (Delft, the Netherlands) (Figure 3) on two occasions; 'regular' (i.e., boarding without the GHL-System, which represent the regular boarding procedure as it is currently used by most airlines) and according to a 'new' boarding process using the GHL-System (including pre-reserved luggage spots for the passengers, guiding light effects and both visual, and textual luggage divisions in the overhead bins). Participants were assigned a seat out of four rows of six seats, with corresponding overhead lockers located exactly above the seats on each side. The guiding icons and lights of the GHL-System were installed in four overhead bins, providing space for approximately 18 bags. Next to the two groups who boarded the plane twice, a third group participated as a control group and boarded twice according to the regular boarding process to determine a possible learning effect. 


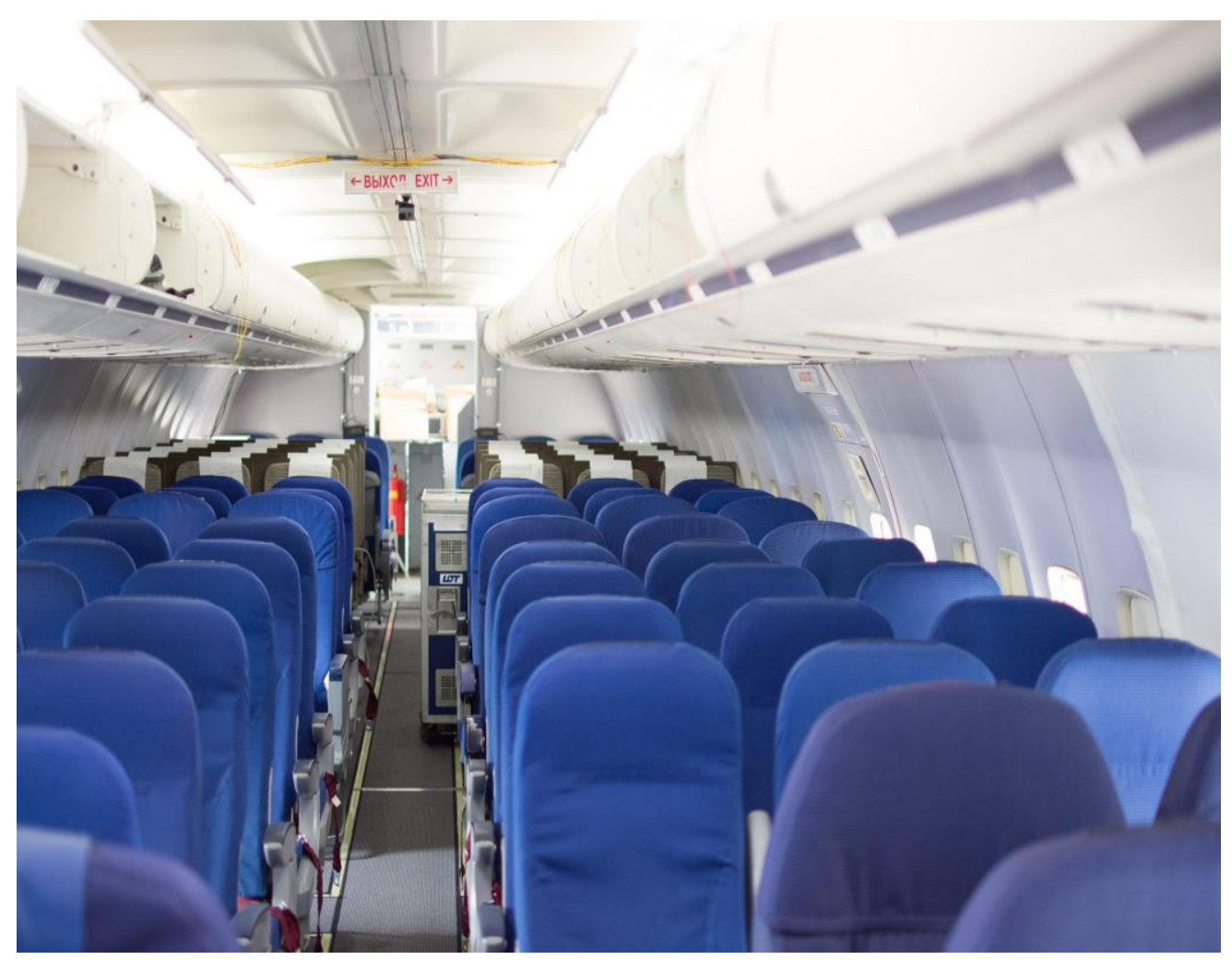

Figure 3. Interior of the Boeing 737 test fuselage used in the test.

\section{Participants}

The participants were either student or staff from TU Delft. Different nationalities were represented with participants coming from India (41.5\%), The Netherlands (24.5\%), Spain (7.5\%), Indonesia (5.7\%), the USA (5.7\%), Great-Britain (3.8\%), Iran (3.8\%), Italy (3.8\%), Finland (1.9\%), and South Korea $(1.9 \%)$. The distribution according to groups, gender and age is shown in Table 1. 
Table 1

Participants Distribution According to Groups, Gender and Age

\begin{tabular}{|c|c|c|c|c|c|c|c|}
\hline \multicolumn{8}{|c|}{ Group 1} \\
\hline \multicolumn{2}{|c|}{$20-29$} & \multicolumn{2}{|c|}{$30-39$} & \multicolumn{2}{|c|}{$40-49$} & \multicolumn{2}{|c|}{$50+$} \\
\hline M & $\mathrm{F}$ & $\mathrm{M}$ & $\mathrm{F}$ & M & $\mathrm{F}$ & M & $\mathrm{F}$ \\
\hline 13 & 2 & 0 & 0 & 1 & 0 & 1 & 0 \\
\hline \multicolumn{8}{|c|}{ Group 2} \\
\hline \multicolumn{2}{|c|}{$20-29$} & \multicolumn{2}{|c|}{$30-39$} & \multicolumn{2}{|c|}{$40-49$} & \multicolumn{2}{|c|}{$50+$} \\
\hline $\mathrm{M}$ & $\mathrm{F}$ & $\mathrm{M}$ & $F$ & $\mathrm{M}$ & $\mathrm{F}$ & $\mathrm{M}$ & $\mathrm{F}$ \\
\hline 11 & 2 & 3 & 1 & 0 & 0 & 0 & 1 \\
\hline \multicolumn{8}{|c|}{ Group 2} \\
\hline \multicolumn{2}{|c|}{$20-29$} & \multicolumn{2}{|c|}{$30-39$} & \multicolumn{2}{|c|}{$40-49$} & \multicolumn{2}{|c|}{$50+$} \\
\hline $\mathrm{M}$ & $\mathrm{F}$ & $\mathrm{M}$ & $\mathrm{F}$ & $\mathrm{M}$ & $\mathrm{F}$ & $\mathrm{M}$ & $\mathrm{F}$ \\
\hline 10 & 2 & 1 & 0 & 1 & 1 & 0 & 2 \\
\hline
\end{tabular}

\section{Stimuli}

For the new boarding procedure, four overhead bins in the Boeing 737 test fuselage of the TU Delft were provided with LED strips and prototyped screens made from paper which indicated how the luggage should be stowed by icons and seat numbers (Figures 1 and 2). When testing the regular boarding situation, these guiding elements were covered making it look normal.

The LED light strip interacted with the passengers according to the light effects described earlier (paragraph 'Light effects'). During the new boarding process, the GHL-System included a predetermined luggage division for the division of the 18 bags in the four bins for this test (see Figures 4 and 5). During the regular boarding process, the same luggage was used but the participants were free to place the luggage as they seemed fit, but using the same four overhead bins. 


\begin{tabular}{|l|l|l|l|}
\hline Round & 2 & Destination & Hawaii \\
\hline Participant number & 4 & Boarding time & $16: 00$ \\
\hline \multicolumn{2}{|l|}{ Seat number } & Luggage: Suitcase and jacket \\
\hline
\end{tabular}

Figure 4. Boarding pass.

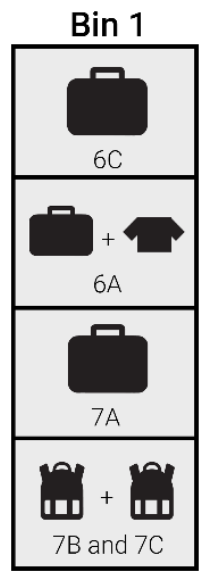

Bin 2

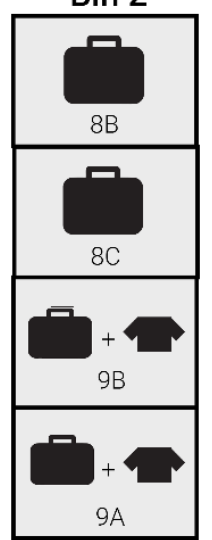

Bin 3

Walking direction
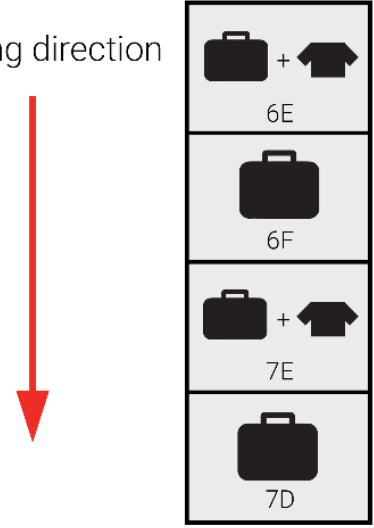

Bin 4

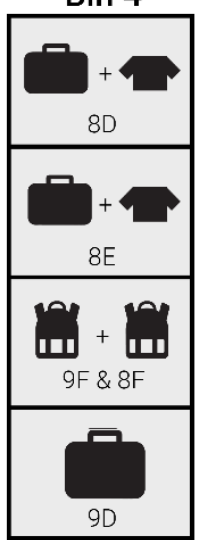

Figure 5. Luggage division to place all 18 bags in the four selected bins. 


\section{Apparatus}

The following equipment was used in the user test:

- A fuselage with enough overhead bins and seats for 18 people.

- Four overhead bins, each with guiding lights, seat numbers and luggage divisions inside. The light effects were controlled by hand; therefore, four people were needed to assist in controlling the lights of all four bins.

- Eighteen (18) coloured safety jackets. On each jacket, the participant number was written down to make sure, participants were lining up in the correct order.

- One-hundred-eight (108) boarding passes (every round, all participants received a new boarding pass). The pass included seat number, round number, participant number and the luggage of that particular participant (Figure 4).

- Twelve (12) normal suitcases, 2 small suitcases, 4 backpacks and 7 jackets to use as luggage.

- Questionnaires for each group and consent forms to assure that PASSME could use the video footage.

- Two GoPro cameras to record the boarding process from two different angles, one from the front and one from the back of the airplane.

\section{Procedures}

During the new boarding situation, the GHL-System was 'learning' the users how to make the luggage fit. As a consequence, it was not possible to test the regular situation after the new situation due to a relatively large learning effect. Therefore, it was chosen to let the groups first board in the regular situation before boarding the new situation. Also, in this case there might be a learning effect as was shown in a previous study (Coppens et al., 2018). To estimate the size of this learning effect, a third group of participants (the control group) tested the regular situation twice to see what the learning effect was without the GHL-System. This test was performed first. The control group was also asked to board a third time, which was used as a pilot study for the new situation (Table 2). 
Table 2

Experimental set-up of the three groups and test rounds

\begin{tabular}{|l|l|l|l|}
\hline & Round 1 & Round 2 & Round 3 \\
\hline $\begin{array}{l}\text { Group 1: Control } \\
\text { group (n=17) }\end{array}$ & Regular situation & Regular situation & $\begin{array}{l}\text { Pilot test new } \\
\text { situation }\end{array}$ \\
\hline Group 2 $(\mathrm{n}=18)$ & Regular situation & New situation & - \\
\hline Group 3 $(\mathrm{n}=18)$ & Regular situation & New situation & - \\
\hline
\end{tabular}

Boarding time and boarding experience were measured during and after each condition by the 2 groups that would board in the regular and new situation under comparable conditions. The participants received other luggage, seat numbers, and bin locations each round.

After each boarding round, all participants were given a questionnaire and a pencil. While completing the questionnaire, they all received cookies and something to drink to thank them for participating.

\section{Validation}

To get reliable results from each test round and to create a near identical environment as an actual plane the following choices were made.

- During each test round the same seat order was used (meaning that the first passenger to board was for example always seated at seat $16 \mathrm{E}$, the second always at $17 \mathrm{~B}$, etc.). With another seat order more aisle interferences could occur. This is because more people might have to get up out of their seat compared to the other seat order. So, using the same seat order decreased the chance of it influencing the boarding time and experience.

- This was also the case for the luggage order (first boarding passenger of every test has a suitcase and jacket, the second passenger only a small backpack, etcetera). More interferences could occur because of suitcase combinations that fit worse compared to the other luggage order. So, using the same luggage order decreased the chance of it influencing the boarding time and experience.

- During each round there was a different participant order. This decreased the chance of a learning effect. 
- The test had a boarding randomness. This was done by letting half the participants board from window to aisle and half from aisle to window. This way, a normal boarding procedure without smart boarding or seat allocation was mimicked.

- The test had a systematic variation in luggage. This means that not only small bags or only big bags boarded after each other. Making sure that it was not too easy or too difficult to store the luggage.

- The boarding location of the participants during the second round did not differ too much from the first round to be sure their location did not have an effect on their experience but only the system had. So, someone who boarded first in the first round did not board last in the second round.

- Half of the time, two participants of the same bin were boarding directly behind each other, other times only one participant per bin boarded. This simulated solo travellers and duo travellers.

- Two bins (bins 1 and 4) had 5 pieces of luggage instead of 4 (Figure 5). It was deliberately chosen to pick two bins which were located diagonally from each other to make sure that the participants were less likely to learn from what happened at the other bins.

- Not all rows were filled with people, since 18 people were distributed over 4 rows of chairs. This means that some seats were empty. These empty seats were distributed equally between window seats, middle seats or aisle seats.

\section{Measures}

The observation part is split into two parts. First, the observations from the original boarding process are documented and afterwards the observations from the boarding process with the implemented guiding system are documented.

Stress and rush of participants was recorded in the questionnaire, using a 7-point Likert (1932) scale (this scale was also used to see whether participants experienced the boarding process as negative, difficult or slow and whether it resulted in long queues). Furthermore, the ease of storing luggage and finding the seat was evaluated using the 7-point Likert scale again. The participants were asked whether they preferred the first round or the second and whether they had suggestions regarding boarding process. The result of the Likert scale ratings was analysed using the Wilcoxon signed rank test (SPSS, 2013), in order to determine statistically significant differences.

The boarding time was measured based on the video recordings of the test (the start was marked by the first participant entering the fuselage, and the ending was marked by the last participant to sit with all luggage properly placed and all the bins closed). 
Furthermore, an extended observation on the following aspects was done using the video footage.

- Hold-ups (any 2 or more consecutive passengers stopped for more than two seconds) in queue and the reason behind it

- Arrangements of luggage in general by the participants

- Where participants looked, before, during and after placing the luggage and seating.

\section{Results}

\section{Boarding Time}

Table 3 shows the recorded boarding time of each boarding round of all three groups. The control group, was 30 seconds faster in the second round. So even without the new GHL-System, a time reduction of $17 \%$ was achieved by repetition.

The other groups (group 2 and 3) show a reduction of 52 and 44 seconds, respectively, in the second boarding round, which might be due to the GHLSystem, but is partly caused by the learning effect. The $17 \%$-time reduction of the control group is therefore used to indicate the learning effect in the other two groups. By subtracting the calculated learning effect from the reduced boarding time, the influence of the GHL-system on the boarding time could be estimated. In this case, the system saved 23 seconds in group 2 and 16 seconds in group 3 (Table 4).

Table 3

Recorded Boarding Time

\begin{tabular}{|l|l|l|l|}
\hline & $\begin{array}{l}\text { Boarding time } \\
\text { round 1 }\end{array}$ & $\begin{array}{l}\text { Boarding time } \\
\text { round 2 }\end{array}$ & $\begin{array}{l}\text { Reduced } \\
\text { boarding time } \\
\text { (boarding time } \\
\text { round 1 minus } \\
\text { round 2) }\end{array}$ \\
\hline $\begin{array}{l}\text { Group 1 (control } \\
\text { group) }(\mathrm{n}=17)\end{array}$ & $181 \mathrm{sec}$ & $151 \mathrm{sec}$ & $30 \mathrm{sec}$ \\
\hline Group 2 (n=18) & $175 \mathrm{sec}$ & $123 \mathrm{sec}$ & $52 \mathrm{sec}$ \\
\hline Group 3 $(\mathrm{n}=18)$ & $166 \mathrm{sec}$ & $122 \mathrm{sec}$ & $44 \mathrm{sec}$ \\
\hline
\end{tabular}


Table 4

Time Reduction Including and Excluding the Estimated Learning Effect

\begin{tabular}{|l|l|l|l|}
\hline & $\begin{array}{l}\text { Reduced } \\
\text { boarding time in } \\
\text { the second round }\end{array}$ & $\begin{array}{l}\text { Estimated } \\
\text { learning effect }\end{array}$ & $\begin{array}{l}\text { Time reduced by } \\
\text { the GHL-system }^{3}\end{array}$ \\
\hline Group 2 $(\mathrm{n}=18)$ & $52 \mathrm{sec}$ & $29 \mathrm{sec}$ & $23 \mathrm{sec}$ \\
\hline Group 3 $(\mathrm{n}=18)$ & $44 \mathrm{sec}$ & $28 \mathrm{sec}$ & $16 \mathrm{sec}$ \\
\hline
\end{tabular}

1 [Boarding time round 1] minus [boarding time round 2] (table 3)

${ }^{2} 17 \%$ of the boarding time in round 1 (table 3 )

${ }^{3}$ [Boarding time round 1] minus [boarding time round 2] minus [estimated learning effect]

\section{Boarding Experience}

Results semantic differential scale.

Figure 6 shows the average results of the control group. Figure 7 shows the results of all participants who tested the GHL-System during their second boarding round (group 2 and 3 combined). Both graphs show differences in all rated factors for the two boarding rounds. 


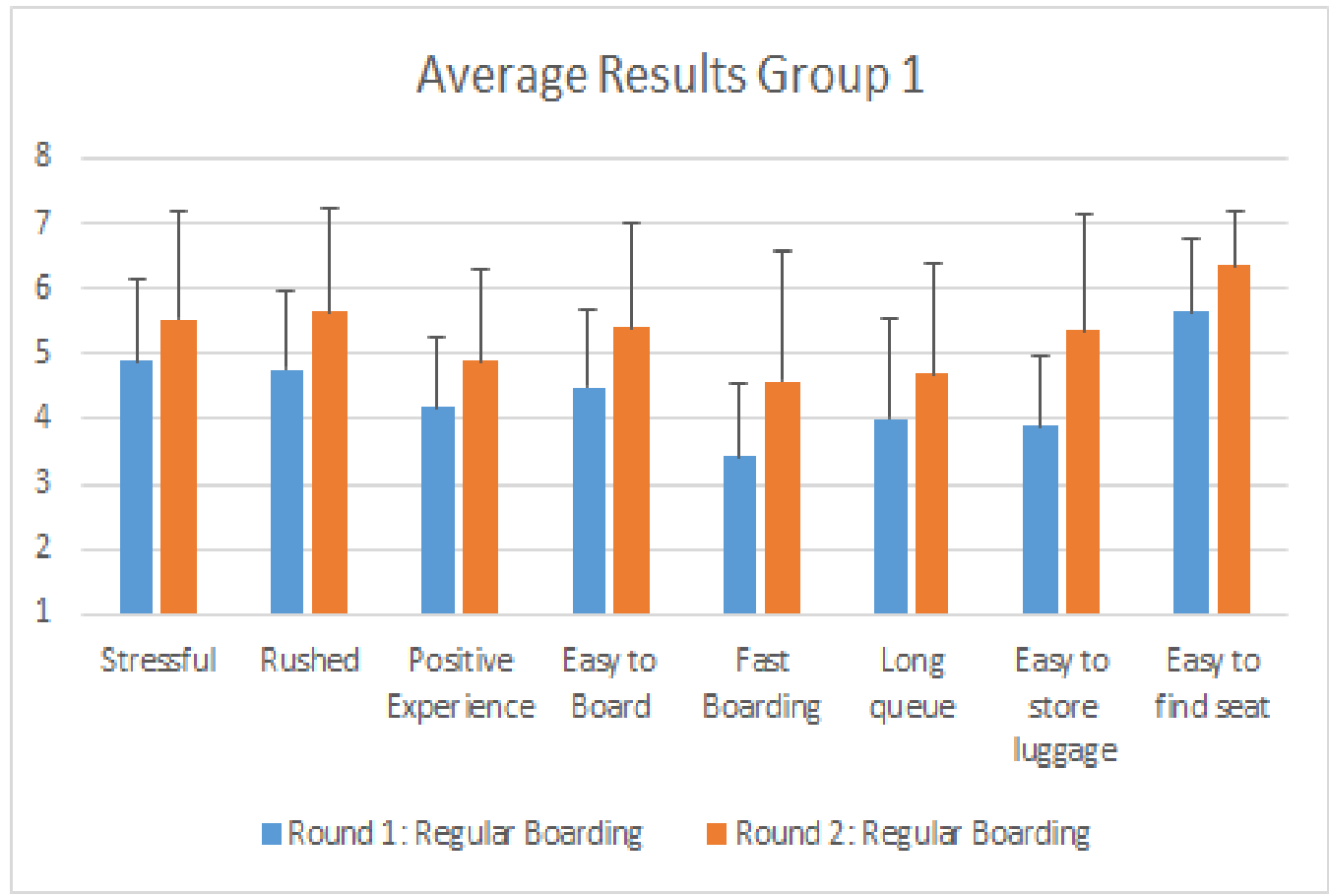

Figure 6. Evaluation Original system based on a semantic differentiation scale rating: $1=$ not at all; $7=$ very much $(n=17)$

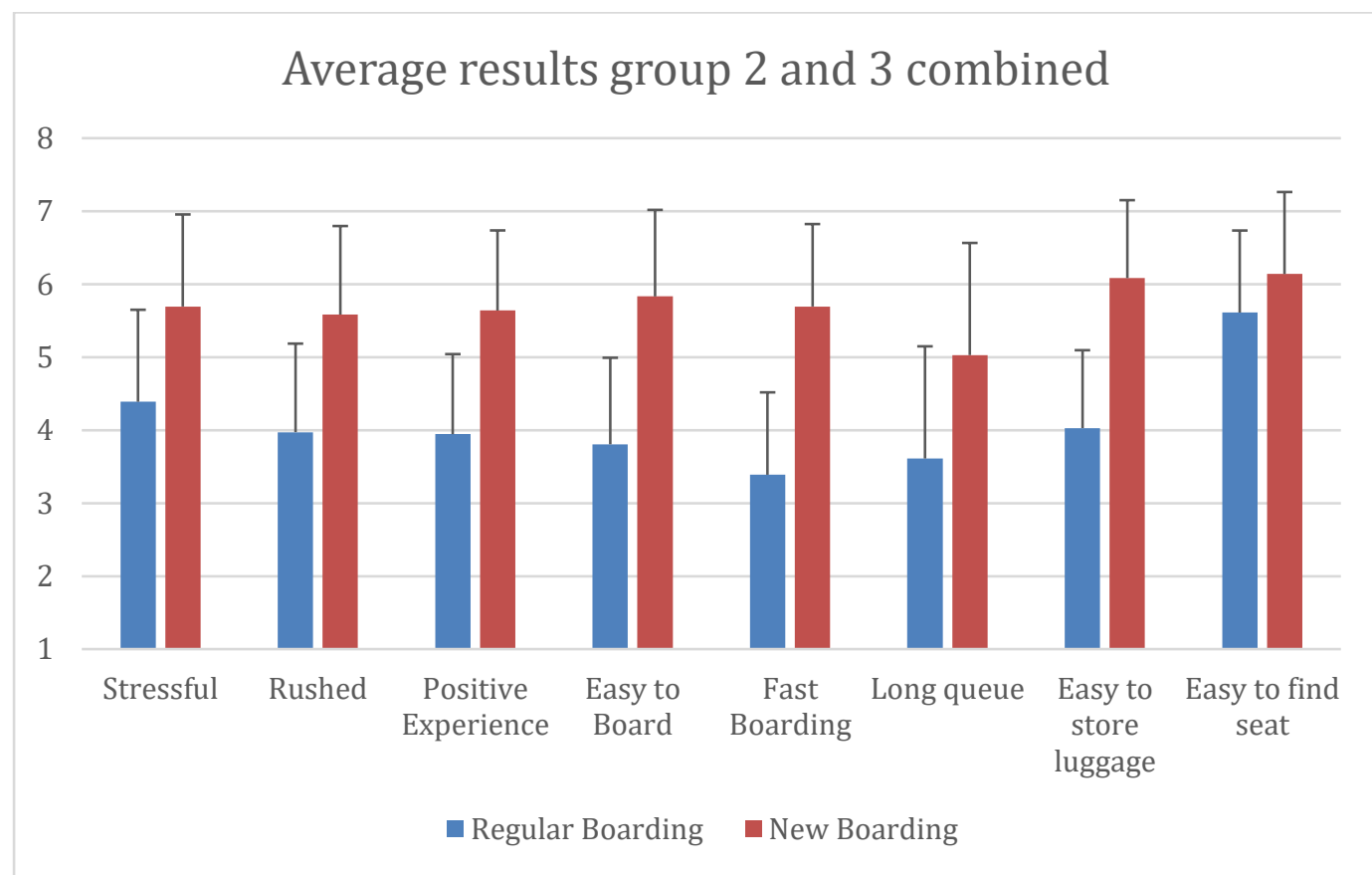

Figure 7. Evaluation Original system based on a semantic differentiation scale rating: $1=$ not at all; 7 = very much. $(n=36)$ 
According to the results (Table 5), the control group showed a significant difference in the rating of positive experience $(\mathrm{p}=0.048)$, easy to board $(\mathrm{p}=0.020)$, easy to store luggage $(\mathrm{p}=0.017)$, and fast boarding $(\mathrm{p}=.024)$. However, in comparison to regular boarding, the GHL-system boarding showed a very high significant difference $(\mathrm{p}<0.01)$ on all examined criteria, except for easy to find seat, which still showed a significance difference of $(\mathrm{p}=0.013)$. In other words, participants favoured all the tested aspects of boarding experience of the new GLS-System compared to the regular boarding.

\section{Table 5}

Wilcoxon sign rank test significance values for control group (first boarding vs second boarding $n=17$ ) and Group $2 \& 3$ (old vs new, $n=36$ ). (Null hypothesis rejected at significance $p<0.05)$, Very high significance at $p<0.01$

\begin{tabular}{|c|c|c|c|c|c|c|c|c|}
\hline & Stressful & Rushed & $\begin{array}{l}\text { Positive } \\
\text { Experien } \\
\text { ce }\end{array}$ & $\begin{array}{l}\text { Easy to } \\
\text { Board }\end{array}$ & $\begin{array}{l}\text { Fast } \\
\text { Boarding }\end{array}$ & $\begin{array}{l}\text { Long } \\
\text { Queue }\end{array}$ & $\begin{array}{l}\text { Easy to } \\
\text { store } \\
\text { luggage }\end{array}$ & $\begin{array}{l}\text { Ea } \\
\text { sy } \\
\text { to } \\
\text { Fi } \\
\text { nd } \\
\text { se } \\
\text { at }\end{array}$ \\
\hline $\begin{array}{l}\text { Significance } \\
\text { Control group } \\
\left(1^{\text {st }} \text { boarding }\right. \\
\left.\text { vs } 2^{\text {nd }}\right)(n=17)\end{array}$ & 0.192 & 0.127 & $0.048 *$ & $0.020 *$ & $0.024 *$ & 0.131 & $0.017 *$ & $\begin{array}{l}0 . \\
06 \\
6\end{array}$ \\
\hline $\begin{array}{l}\text { Significance } \\
\text { Group } 2 \& 3 \\
\text { (old vs new) } \\
(\mathrm{n}=36)\end{array}$ & $<0.001^{*}$ & $<0.001^{*}$ & $<0.001 *$ & $<0.001 *$ & $<0.001 *$ & $0.001^{*}$ & $<0.001 *$ & $\begin{array}{l}0 . \\
01 \\
3 *\end{array}$ \\
\hline
\end{tabular}

\section{Suggestion for improvement of the overall boarding process.}

The participants presented some suggestions about aspects of the boarding process which still need improvement. These suggestions included thoughts to make it easier to find your seat and to avoid confusion between the aisle seat and window seat. It is mentioned that the original seat numbers for finding your seat in airplanes are too small.

Another suggestion for improvement refers to the boarding order. The majority of the participants mentioned changing the boarding order to make sure window seats board first. This is indicated to have a positive effect; however, it is hard to implement from an organizational point of view (Steffen, 2008). 


\section{Boarding Preference}

In the control group, who experienced the same original situation in both boarding rounds, $69 \%$ preferred the second round. For those who experienced the GHL-System in the second round, $92 \%$ chose this round as a favourite (Table 6).

Table 6

Boarding preference

\begin{tabular}{|l|l|l|}
\hline & $\begin{array}{l}\text { Group 1 } \\
\text { (Round 1: Original; } \\
\text { Round 2: Original) } \\
(\mathrm{n}=17)\end{array}$ & $\begin{array}{l}\text { Group 2 and 3 } \\
\text { (Round 1: Original; } \\
\text { Round 2: New) (n=36) }\end{array}$ \\
\hline Prefered boarding round 1 & $31 \%$ & $8 \%$ \\
\hline Preferred boarding round 2 & $69 \%$ & $92 \%$ \\
\hline
\end{tabular}

Within groups 2 and 3, there was a total of 3 participants (8\%) who preferred the original situation boarding process above the new process. According to their additional comments, one of them experienced a wrongly placed suitcase, causing the dissatisfaction about round 2. Another participant did not have any troubles with the luggage in the first boarding round: "I was quite early and there was plenty of room." However, the same participant added that "Overall, the first round was slower."

\section{Open Questions}

Both the control group as well as the other participants gave their opinion about the boarding experience in both rounds.

\section{Control group.}

According to participants the original boarding round was perceived as "similar to current practice" and "seemed like the standard stressful boarding procedure." Therefore, the original boarding round might be seen as a fair comparison to an actual boarding process. The second boarding round of group 1 was described as "easier to board and less stressful" due to the fact that they "were acquainted with the process." Although the participants did not agree upon which round, they preferred best. Among 18 participants, four described the first round as "faster" but seven participants mentioned the second boarding 
round to be better due to "more practise." It was "fast", "much easier to find the seat and store the luggage", there was "no rush" and they were "already familiar with the layout" of the fuselage. Furthermore, group 1 confirmed the defined problem of luggage storage. They suggested improvement of the boarding "speed", "more luggage space" and "organizing storage."

\section{Groups 2 and 3.}

Similar to the control group, the first boarding round reminded participants of a usual flight. It was chaotic, messy and difficult to find luggage space, taking a lot of time and causing anxiety stress and frustration. "It definitely shows that the most difficult task is to find place for hand luggage." In the second round it was easier to store luggage, making the process faster and simpler, creating satisfaction and a more efficient, relaxed and a "much more organised" process. But the GHL-System also caused some stress and insecurity for those who were afraid to make mistakes or did not understand the guiding lights. The video observations from the video showed that the queues were shorter, and the open questions in the questionnaire showed less worries and insecurities about luggage space as the lights indicated the locations. It was easier to find luggage space and thereafter to fit the bag in the bin. "Simple but efficient."

\section{Observations}

\section{Original Boarding Process}

The observation showed that the participants had to look at their boarding pass and the seat number on the bottom of the bins multiple times before finally sitting down. Furthermore, a few participants were sitting in the wrong seats. The participants were also more focussed on placing luggage than finding the right seat resulting in them holding up the line when searching for their seat after placing their luggage.

It was observed that participants found it difficult to find a good luggage spot causing queue formation. Participants needed a lot of time to find a spot and placed luggage in the bins which were sometimes excessively far from their seat. Besides this, people placed their luggage in the first bins while having a seat in the back of the plane. So, they occupied spots from participants entering the plane in a later stage with their seats near the first bins. Because of this, the participants with a seat in the beginning of the plane had to walk to the back to find a luggage spot. So, after placing the luggage, some participants had to walk against the participant stream causing holdups. Furthermore, participants used force to make their luggage fit. This is not preferred because fragile luggage would break when another piece of luggage is pushed on top of it with a lot of force. 
Finally, there were not that many spots left at the end of the boarding process and participants were forced to rearrange suitcases to make their own luggage fit. As mentioned in the method the participants partly entered the plane following the smart boarding principle and partly in a random order. The partly random and partly organised boarding order resulted in passenger jams. People had to stand up from their seat to let other people pass and sit. This caused row interference and was a big cause for the overall boarding delay.

There were some considerate passengers with a middle or aisle seat who waited for the other passengers from the same row. Only when the passengers from the same row were seated these considerate passengers would sit down. This resulted in faster boarding. Unfortunately, only two people of all 53 people did this.

\section{New Boarding Process}

- No one had to walk against the passenger stream and all bins could be closed at the end of boarding without having to rearrange luggage. Furthermore, no extra force was needed to place the luggage since there was a clear spot for everyone. Only one participant misplaced his/her luggage.

- The amount of hold ups, caused by passengers searching their seat after placing their luggage, was reduced. Passengers sat down faster and found their seat easier. Moreover, the focus of the participants completely changed from finding any empty luggage spot to finding the personal seat number shown in the bins.

- People still had to get up to let people sit on the seats next to them.

- The majority of the participants were not looking at the top of the bin when placing the luggage. Because of this, it is not sure if all participants have seen the green- or red-light effect.

\section{Discussion}

In answering the research question, boarding with the GHL-system conditions seems to be faster. However, boarding the second time in a regular situation is faster as well and is in line with earlier studies that show a learning effect (Coppens et al., 2018). The boarding experience with the GHL-System is clearer as there are significant differences between the two boarding conditions, which were not found in the control group.

\section{Decreased Boarding Time}

Based upon the results of the control group, it appeared that the biggest time difference was caused by a learning effect. However, even when the influential learning was subtracted from the result, the GHL-System is estimated to reduce the boarding time by 16 to 23 seconds for 18 passengers. Additionally, 
Kierzkowski and Kisiel (2017) reported that traditional hand luggage handling of passengers increases boarding time.

The time reduction of the GHL-System corresponds to 3 to 4 minutes of boarding time reduction on a Boeing 737-800 aircraft with 189 passengers. This is only a part of what Nyquist and McFadden (2008) calculated, estimating that the time saved by eliminating all hand luggage would be 11 minutes for a flight with a boarding time of 20 minutes.

Observing the test footage gave insight on the aspects that influenced the boarding time using GHL-System; No luggage rearranging was needed. Furthermore, no passenger had to walk against the passenger stream as the luggage could be placed in the bins close to the arranged seat.

\section{Boarding Experience}

All groups described the first boarding round as similar to the normal boarding processes during real flights. This indicates that the user test setup is likely to be realistic and comparable to real current boarding situations.

The control group as well as the groups who tested the GHL-System rated the experience higher on all evaluated aspects (positive experience, easy to board, easy to store luggage, fast boarding) during the second boarding round, however for normal boarding procedure of second round (group 1), only "positive experience" and "fast boarding" was rated significantly higher $(<0.5)$. Whereas for the GHL-System, all the experiences except "easy to find seat" were rated very significantly higher $(<0.01)$.

Some participants of group 2 and 3 mentioned to experience fear and insecurity to make mistakes and others were a bit confused by the lights. This feeling of confusion was also visible on the video footage. The majority of the participants were not looking at the top of the bin when placing the luggage. Because of this there is a chance that not all participants have seen the light effects, resulting in confusing when reading the questions about the light system. Overall these negative emotions were minor compared to the advantages the system had to offer and the removed insecurities about luggage space. So, it can be concluded that the GHL-System has potential to improve the passengers' experience compared to a normal boarding process and further studies in real flights are advised.

This improved experience is confirmed by $92 \%$ of the participants who preferred the second round. A $100 \%$ satisfaction was anticipated but based on the open questions it became clear that participants' experience was not only based on the influence of the GHL-System. Their opinion also depended on factors as order in line, big or small luggage, seat location and the luggage distribution at the start of the test. Three participants did not prefer the boarding round with the GHL-System of whom one based this decision on an 
(un)fortunate order in line in one of the rounds which has nothing to do with the tested concept. However, the satisfaction of the GHL system was significant higher compared to the control group. And it can be analysed whether further improvements of the concept can increase the satisfaction from $92 \%$ up to $100 \%$ of the users.

From the observations it could be concluded that the increase in experience perception is probably due to less hold ups caused by passengers searching their seat after placing their luggage inside the bins. Passengers sat down faster and found their seat more easily. Finally, it was observed that when placing luggage, no extra force was needed since there was a clear spot for everyone. This might have also increased the experience of the passengers.

\section{Learning Effect}

In all scenarios the learning effect had to be taken into account and estimations had to be made to determine the actual influence of the GHLSystem and the impact of learning of which the results are discussed above. The focus of this research was to identify the ability of a guiding hand luggage system to reduce boarding time and improve the experience. And indeed, this study indicates that time could be saved by the GHL-System. Yet an even bigger improvement in time was reached by the learning effect. By repeating the same boarding process, up to 30 seconds was saved by a group of 17 boarding passengers. This was likewise described by Coppens et al. (2018). Proper preparation of the passengers before boarding or another way of learning what to expect could significantly reduce boarding time, which is certainly an area to study further. This test showed a decreased in time of $17 \%$ by repetition of the process, but a similar test should be repeated with several more control groups on actual flights to further confirm these results.

\section{Limitations}

This research was done with groups of 18 participants. Since common flights do have significantly more passengers, the effect of GHL on a larger scale is yet unknown. Furthermore, this research was limited by only three groups of participants. In addition to this, the test was done during day light condition of aircraft, how these results translate to night lighting conditions is unknown. Furthermore, as the participants were students and staff from TU Delft, it is possible that they are more adept at adjusting to new situations than the average population, and this could have influenced the results as well. It is recommended to do a large-scale test to measure the timesaving with larger and more diverse groups. By increasing the number of tests, the accuracy of the results can be further improved. 


\section{Conclusions}

The GHL-system did convincingly reduce the stress level and rush while boarding and indicated a time saving of 3-4 minutes on a Boeing 737-800 flight with 189 passengers. Giving the participants their personal luggage spot which is located near their seat can solve the problem of passengers not being able to find a good luggage spot and queue formation. Furthermore, the boarding experience was observed to be more positive and improved the ease of boarding, the perceived boarding speed and the queue length. Further research is needed on actual flight conditions to prove the effect of this system.

\section{Acknowledgements}

The authors would like to thank all the participants for volunteering in this study.

This study has been part of the research project PASSME, which has received funding from the European Union's Horizon 2020 research and innovation programme under grant agreement No 636308. 


\section{References}

Coppens, J., Dangal, S., Vendel, M., Anjani, S., Akkerman, S., Mastrigt, S. H., \& Vink, P. (2018). Improving airplane boarding time: A review, a field study and an experiment with a new way of hand luggage stowing. International Journal of Aviation, Aeronautics, and Aerospace. doi:10.15394/ijaaa.2018.1200

Iskra-Golec, I., Wazna, A., \& Smith, L. (2012). Effects of blue-enriched light on the daily course of mood, sleepiness and light perception: A field experiment. Lighting Research \& Technology, 44(4), 506-513. doi:10.1177/1477153512447528

Jaehn, F., \& Neumann, S. (2015). Airplane boarding. European Journal of Operational Research, 244(2), 339-359. doi:10.1016/j.ejor.2014.12.008

Kierzkowski, A., \& Kisiel, T. (2017). The human factor in the passenger boarding process at the airport. Procedia Engineering, 187, 348-355. doi:10.1016/j.proeng.2017.04.385

Likert, R. (1932). A Technique for the Measurement of Attitudes. Archives of Psychology. 140: 1-55. Retrieved from https://legacy.voteview.com/pdf/Likert_1932.pdf

Luo, M. R., Zhao, F., Zhai, Q., Liu, X., \& Wang, B. (2013). The impact of LED on human visual experience. 2013 10th China International Forum on Solid State Lighting (ChinaSSL). doi:10.1109/sslchina.2013.7177370

Nyquist, D. C., \& Mcfadden, K. L. (2008). A study of the airline boarding problem. Journal of Air Transport Management, 14(4), 197-204. doi:10.1016/j.jairtraman.2008.04.004

PASSME. (2017). About PASSME. Retrieved on 01-09-2017, from http://www.passme.eu/about-passme

Steffen, J. H. (2008). Optimal boarding method for airline passengers. Journal of Air Transport Management, 14(3), 146-150. doi:10.1016/j.jairtraman.2008.03.003

Steffen, J. H., \& Hotchkiss, J. (2012). Experimental test of airplane boarding methods. Journal of Air Transport Management, 18, 64-67.

SPSS, I. (2013). IBM SPSS statistics 25. New York: IBM Corp.

Van der Broek, X. M. (2015). Solving KLM's hand luggage problem (Masters thesis). Delft University of Technology, Delft, the Netherlands. 
International Journal of A viation, Aeronautics, and Aerospace, Vol. 6 [2019], Iss. 3, Art. 5

Veitch, J., Newsham, G., Boyce, P., \& Jones, C. (2008). Lighting appraisal, well-being and performance in open-plan offices: A linked mechanisms approach. Lighting Research \& Technology, 40(2), 133151. doi:10.1177/1477153507086279 


\section{Appendix}

Seating configuration of participants

\begin{tabular}{|c|c|c|c|c|c|c|c|c|}
\hline \multirow[t]{2}{*}{$\begin{array}{l}\text { Boarding } \\
\text { order }\end{array}$} & \multicolumn{4}{|c|}{ Round 1 (regular situation) } & \multicolumn{4}{|c|}{$\begin{array}{l}\text { Round } 2 \text { (new situation or regular situation, } \\
\text { depending on the group) }\end{array}$} \\
\hline & $\begin{array}{l}\text { Participant } \\
\text { number }\end{array}$ & $\begin{array}{l}\text { Seat } \\
\text { number }\end{array}$ & Luggage & Bin & $\begin{array}{l}\text { Participant } \\
\text { number }\end{array}$ & $\begin{array}{l}\text { Seat } \\
\text { number }\end{array}$ & Luggage & Bin \\
\hline 1 & 1 & $7 \mathrm{C}$ & Backpack & Bin 1 & 18 & $7 \mathrm{C}$ & Backpack & Bin 1 \\
\hline 2 & 2 & $7 \mathrm{~A}$ & Suitcase & Bin 1 & 1 & $7 \mathrm{~A}$ & Suitcase & Bin 1 \\
\hline 3 & 3 & $9 \mathrm{~A}$ & $\begin{array}{l}\text { Suitcase } \\
+ \text { jacket }\end{array}$ & $\operatorname{Bin} 2$ & 2 & $9 \mathrm{~A}$ & $\begin{array}{l}\text { Suitcase + } \\
\text { jacket }\end{array}$ & Bin 2 \\
\hline 4 & 4 & $7 \mathrm{E}$ & $\begin{array}{l}\text { Suitcase } \\
+ \text { jacket }\end{array}$ & $\operatorname{Bin} 3$ & 3 & $7 \mathrm{E}$ & $\begin{array}{l}\text { Suitcase + } \\
\text { jacket }\end{array}$ & Bin 3 \\
\hline 5 & 5 & $6 \mathrm{E}$ & $\begin{array}{l}\text { Suitcase } \\
+ \text { jacket }\end{array}$ & Bin 3 & 4 & $6 \mathrm{E}$ & $\begin{array}{l}\text { Suitcase + } \\
\text { jacket }\end{array}$ & Bin 3 \\
\hline 6 & 6 & $8 \mathrm{D}$ & $\begin{array}{l}\text { Suitcase } \\
+ \text { jacket }\end{array}$ & $\operatorname{Bin} 4$ & 5 & $8 \mathrm{D}$ & $\begin{array}{l}\text { Suitcase + } \\
\text { jacket }\end{array}$ & Bin 4 \\
\hline 7 & 7 & $7 \mathrm{~B}$ & Backpack & Bin 1 & 6 & $7 \mathrm{~B}$ & Backpack & Bin 1 \\
\hline 8 & 8 & $8 \mathrm{C}$ & $\begin{array}{l}\text { (Small) } \\
\text { suitcase }\end{array}$ & Bin 2 & 7 & $8 \mathrm{C}$ & $\begin{array}{l}(\text { Small) } \\
\text { suitcase }\end{array}$ & $\operatorname{Bin} 2$ \\
\hline 9 & 9 & $8 \mathrm{~B}$ & Suitcase & Bin 2 & 8 & $8 \mathrm{~B}$ & Suitcase & Bin 2 \\
\hline 10 & 10 & $6 \mathrm{~F}$ & $\begin{array}{l}(\text { Small }) \\
\text { suitcase }\end{array}$ & Bin 3 & 9 & $6 \mathrm{~F}$ & $\begin{array}{l}\text { (Small) } \\
\text { suitcase }\end{array}$ & Bin 3 \\
\hline 11 & 11 & $8 \mathrm{~F}$ & Backpack & $\operatorname{Bin} 4$ & 10 & $8 \mathrm{~F}$ & Backpack & Bin 4 \\
\hline 12 & 12 & $8 \mathrm{E}$ & $\begin{array}{l}\text { Suitcase } \\
+ \text { jacket }\end{array}$ & Bin 4 & 11 & $8 \mathrm{E}$ & $\begin{array}{l}\text { Suitcase + } \\
\text { jacket }\end{array}$ & Bin 4 \\
\hline
\end{tabular}




\begin{tabular}{|l|l|l|l|l|l|l|l|l|}
\hline 13 & 13 & $6 \mathrm{~A}$ & $\begin{array}{l}\text { Suitcase } \\
+ \text { jacket }\end{array}$ & Bin 1 & 12 & $6 \mathrm{~A}$ & $\begin{array}{l}\text { Suitcase + } \\
\text { jacket }\end{array}$ & Bin 1 \\
\hline 14 & 14 & $6 \mathrm{C}$ & Suitcase & Bin 1 & 13 & $6 \mathrm{C}$ & Suitcase & Bin 1 \\
\hline 15 & 15 & $9 \mathrm{~B}$ & $\begin{array}{l}\text { Suitcase } \\
+ \text { jacket }\end{array}$ & Bin 2 & 14 & $9 \mathrm{~B}$ & $\begin{array}{l}\text { Suitcase + } \\
\text { jacket }\end{array}$ & Bin 2 \\
\hline 16 & 16 & 7D & Suitcase & Bin 3 & 15 & 7D & Suitcase & Bin 3 \\
\hline 17 & 17 & $9 \mathrm{~F}$ & Backpack & Bin 4 & 16 & 9F & Backpack & Bin 4 \\
\hline 18 & 18 & 9D & Suitcase & Bin 4 & 17 & 9D & Suitcase & Bin 4 \\
\hline
\end{tabular}

\section{The step by step approach}

All participants lined outside the front cabin door in first round boarding order.

Every participant received a safety jacket with a number, the number corresponded with the participant number as well as the boarding order.

Every participant received a piece of luggage and the correct boarding pass.

Instructions were given:

- We will board two times.

- The boarding pass shows your seat number.

- Luggage has to be placed in overhead bins. Only when the luggage does not fit, backpacks and or jackets can be placed underneath the seats.

Boarding round 1 started.

All participants were asked to gather their luggage and bring it back outside, after the boarding process was finished. Here they had to line up again in the same order as before.

The last person in line (number 18) was relocated and placed first in line (as defined in table 2).

All participants were asked to give their luggage to the person in front of them (except participant 18, he or she gave the luggage to number 17 who was the last to board).

All participants received a new boarding pass. 
Instructions were given:

"A new boarding system will be tested in this boarding round in which you all have a predetermined location for your luggage. You will recognise your luggage location by the seat number which is shown in the bins. Furthermore, the lighting will guide you. Make sure you place your luggage on your own spot. Those with a jacket can place the jacket in the same luggage location as their suitcase."

Boarding round 2 started. 